\title{
A ROBOT FOR LEVELLING AND COMPACTION OF CONCRETE
}

Yngve Alvarsson and Larissa Molina

Rollit Innovation, Skogshemsvagen 7 B, S-141 41 Huddinge

Stockholm, Sweden FAX +46-8-7794126

Larissa Molina, CBI, S-100 44 Stockholm

Stockholm, Sweden

\begin{abstract}
The modern attempt in the construction industry is to reduce and replace heavy labor and messy activities with ergonomic methods. Placing and compaction of fresh concrete on a building site is one of such areas. Today it is difficult to recruit young people for this kind of work. For the future it will be necessary to make this heavy work easier. It has to be more attractive for the comming generation and to compensate for eventual shortage of skilled workers. High-quality concreting involves also securing of a dense, outer skin of a concrete for protecting the entire construction against corrosion and erosion, for promoting higher durability. Repairing of bridgedecks by placing a new upper concrete layer often requires external surface vibration and revibration.

A robot has been developed to travel on the fresh concrete surface, externally vibrate the concrete, densify this outer skin and smooth this surface. This Rollit Robot can move itself through the area of freshely placed concrete on the building site. A prototype has been used for repairing bridgedecks with advantage. The project is supported by the Swedish Work Environment Fund and by the selected contractors.
\end{abstract}

\section{INTRODUCTION}

It is well known that vibration and revibration of concrete plays a major role in placing and destributing high-quality concrete $/ 1 /$. One effect of revibration is to reconsolidate the concrete. Other desirable effects are to improve adjacent of the concrete to the reinforcing bars and to reduce the voids caused by settlement and bleeding $/ 1 /$.

There are sufficient needs in many countries to repair a large number of bridgedeck surfaces. Those surfaces have been damaged by erosion and corrosion caused by vehicles and by deicing agents. Deterioration of highway bridgedecks continues to be an enormous problem in forms 
of maintenance and rehabilitation $/ 9 /$.

When repairing the damaged upper part of the deck, the concrete has to be removed and replaced by a new layer. Good bond requires between the resurfacing layer and the old bridgedeck. The thickness of this layer can vary sufficiently. Especially if the high pressure water-jet is used for the removal of the damaged concrete. In the case with the large bridgedeck the amount varies of removed, damaged concrete. Consequently, the thickness of the new layer will differ. Despite thickness variations with following differences in shrinkage, the good bond, required level and flatness have to be achieved. Beside this problems it is often difficuit to get a proper compaction of this new layer.

Sufficient durability of the concrete constructions necessiates a reduction of the contact surface between the concrete and the aggressive compounds ( $\mathrm{f}$ ex deicing agent). Densifying of the concrete outer skin by external revibration has consequently been a good alternative. Partly it has been achieved due to reduction of shrinkage and strength impovement of the interfacial bonds. Additionally, the bond strength between top-cast bars and concrete has been increased in high-slump concrete or for bars affected by settlement and bleeding /1/.

Poker vibrators and/or surface vibrators guided by trackrails are commonly used for the above mentioned type of repairing work. However it has been difficult to achieve desirable flatness by use of these equipment. Without the spoiling of the surface it is difficult to revibrate with poker vibrators or other, nowadays available equipment.

Therefore the Rollit Robot has been developed, in order to travel on the fresh surface, consolidate and level the surface layer and secure the outer skin of the concrete construction.

\section{LEVELLING AND COMPACTION}

In the construction industry when producing large slabs or bridge decks of concrete, there is an old and common problem. All professionals are aware of it. If a labor for any reason needs to get back out on a fresh, newly poured area, he will spoil the surface finish when he walks out. While he is walking back in, leaving the wet area, he has to repair not only the small spots he went out for, but also all his own footprints in the concrete. If the cement is starting to set, he can not walk out at all. It will be very difficult to repair a spoiled surface. Instead he has to come back later for grinding and correcting the hardened surface even for the physical shrinkage cracks of the surface layer, see $\S 3.3 .2$.

A robot, dealing with placing, levelling, vibration etc, has to be carried by a unit, which can walk on a fresh concrete surface. Such a unit is now possible to design and robots for different applications can be made.

By a new invention the possibility has been opened to design equipment for treating of concrete in many different new ways, compared with the traditional production methods. Equipment based on a completely new concept has been developed. Such equipment can move through the area of wet or early setting concrete mass and thereby treate 
the concrete in a non-conventional way. In order to improve the concrete quality, simplify production and promote the ergonomic conditions for the labor, it is now possible to design a robot for concrete placement.

A Rollit Robot may have any size from a small remote-control operated machine to a large, even drivable vehicle, covering the full width of a road or bridgedeck. It can travel directly on the rough placed concrete without any kind of traditional support from i.e. trackrails or formsides. This robot can level, vibrate and smooth the surface. The design is based on a patented principle using an endless belt. This special belt can either move the equipment forward or backward while it floats very lightly on the surface of the fresh concrete mass. There is a motorvibrator mounted on the robot. The transportation speed and the vibration effect can be regulated during the movement of the machine and these both functions can be adjuasted to the actual consistence and/or degree of setting of the concrete.

A small excavator-blade can be mounted at the front of the machine for equalizing the level of the concrete by moving the concrete from a high spot to a low spot. The production capacity can be very high during the levelling of a large slab.

\section{THE INFLUENCE OF VIBRATION}

The strength and durability of concrete in freeze-thaw and deicer environments is determined for the most part by the size and distribution of microscopic (entrained) and entrapped airvoids, cracks, connectivity of the pore system, the bond strength between reinforcement and concrete and between the aggregate and cement paste.

Correct vibration and revibration helps to ahieve desirable characteristics as an adequate air content of entrained air, reduced entrapped air content, a certain specific surface area of the entrained air.

\subsection{COMPACTION}

Efficiency of the vibration generally is given in direct terms of changing porosity of a concrete. Those changes are related to a concrete material itself with the mixture compactability, with and without reinforcement. Compaction will then be measured by $f$ ex degree of compaction. Concrete slump, temperature and bar positions will influent the final effect of vibration on the bond strength, interfacial strength and the quality of the concrete. Low slump, low waterbinder ratio-concrete requires sufficient vibration to achieve the desirable degree of consolidation of the concrete /9/. External revibration is to prefer in this case. Otherwise the structure around the poker vibrator will be disturbed (more porous).

Vibration and revibration change the structure of the pore system. The amount of pores between 10,000-50,000 $\AA$ reduces, while the amount of micro- and mesopores increases. Totaly, a densifying of a concrete is accompanied by the increased plasticity of the fresh 
concrete. The fresh concrete receive the better reological characteristics. Small deviation in the compressive strength on the vertical direction occures /1/. If properly afforded, the correct vibration and revibration lead to decreased permeability, increased ultimate and compressive strength /1/ and durability.

\subsection{SHRINKAGE}

\subsubsection{CHEMICAL SHRINKAGE}

Mixed water filles the pores in the fresh concrete, beside some entrapped air-filled pores. As time going, some water will be used in the chemical reactions of hydration. Then shrinkage, induced by this chemical water consumption, will be called chemical shrinkage. Many LSconcretes show high capability to chemical shrinkage, specially at lack of mixed water.

\subsubsection{PHYSICAL SHRINKAGE}

Beside the chemical drying and -shrinkage water will be dried from the surface, primarily in the surrounding air. Wind, high surrounding temperature or concrete temperature increases drying rate and possibility for the physical shrinkage.

In all cases, after concrete placement and initial curing, the drying of the unprotected surface will be of considerable extent. The shrinkage of the outer layer will then be larger than of the deeper layers. If the outer layer can not resist the tension stresses, caused by this difference, the shrinkage cracks of the surface layer release this tension. Generally, LS-concrete resists better this tension without crack formation.

Especially, the shrinkage cracks can often appear on the unprotected concrete surface. There Rollit Robot can be used with advantage in order to close or reduce the wide of those cracks by compacting- and revibrating action.

\section{BOND IMPROVEMENT}

\subsection{INTERFACIAL BOND BETWEEN AGGREGATE AND PASTE}

This bond is often depending on the porosity of the interface and its wide. External vibration by Rollit Robot assumes to decrease this porosity and wide by better compaction, hardening activation and more homogeneous distribution of water and air voids through the entire concrete body. 


\subsection{REINFORCING BOND}

Effect of revibration on the bond strength between concrete and horizontal deformed bars assumes be influenced by the following parameters $/ 7 /$ :

-concrete slump

-concrete temperature

-bar position

-the time interval between initial vibration and revibration.

At increased concrete temperature, f e $x$ from $16-19^{\prime} \mathrm{C}$ to $26-27^{\prime} \mathrm{C}$, more effort requires to screed the surface and reconsolidate the concrete at age of 90 minuts $/ 1 /$.

Both bond and compressive strengh will increase for concrete with slump below 3-4 in. after applyed revibration $/ 6 /$.

Increase appears in ultimate bond strength of up to $62 \%$ at the delayed external vibration up to 9 hours after placement, compared with nonvibrated concrete $/ 4,5 /$.

\section{IMPROVED QUALITY OF THE SURFACE LAYER}

For most bridgedecks, the aim is to prevent deterioration caused by aggressive agents, penetrating into the concrete body, initiating concrete corrosion, reaching steel reinforcement and initiating steel corrosion $/ 9 /$. Protective system of a dense outer skin at resurfacing is used therefore. The choise of LS-low water to binder ratio overlayer is an additional method. In both cases the lower permeability will reduce penetration of the aggressive ions into the concrete and to the reinforcement $/ 9 /$.

External revibration and vibration help to achieve the dense surface layer with less and/or smaller shrinkage cracks and to improve strength. Revibration can start very early and be repeated in intervalls. It can be repeated many times with lap up to hours after placing.

In the similar way as a roller compactor is used to make the surface of an asfalt road smooth and finished, the Rollit Robot can correct misstakes or stop marks from a surface vibrator. The surface will after a few passes be flatter and normal manual screeding will be eliminated or reduced..

\section{REMOTE-CONTROLLED AND LASER GUIDED PROTOTYPE}

The prototype is provided with a long cabel through which it is possible to control the robot at testing. Remote control by radio will be required for the wide bay construction in the future.

A large, drivable vehicle, with a possibility to ride on, has also been tested. It has many advantages. The operator can visually inspect the achieved result from a close position on the 
top of the vehicle instead of trying to judge the treating result from the far distance at the side of the bay. A ride-on vehicle allows also the operator to make an extra pass over and to correct some surfacing imperfections or irregularities directly and easy.

Rollit Robot has also been tested with an automatic laser-guide system for control of the level or elevation of horizontal slabs.

\section{CONCLUSION}

It is now possible to design equipment which can improve the traditional production methods in building construction. A robot has been developed to travel on the fresh concrete surface, externally vibrate the concrete, densify and smooth this surface. A proper and adequate compaction and repeated revibration of the surface will improve the durability of the entire constructure unit.

The attack on the reinforcement steel will be delaid, the life time of the structure can be extended by use of the Rollit Robot. Wear resistance may also be improved as well as a thin layer bond to the underlaying structure if LS-concrete is used and a proper and adequate compaction from the surface is accomplished.

Companies manufacturing equipment for handling of concrete are looking for the possibility to develope better equipment or design some kind of a robot to replace the heavy manual work. It is necessary to make this kind of work easier and more attractive for the coming generation.

Poker-immersion vibration or surface vibration will seldom guarantee the optimal compaction of the surface layer. Rollit Robot creates a compacted surface layer, which is dense and has a low permeability. Rollit Robot will help to improve the quality of the concrete and to prolong the life of a structure.

\section{FUTURE STUDY}

Future study is planned in actual building sites in cooperation with Scandinavian contractors in order to verify results scientifically and propose the guidelines for the future use of this new tool. All kind of tests, including those on the drilled cores from the structural concrete, would help to establish the practical effects of external revibration by Rollit Robot.

The study on a large scale will include the optimal time interval, which is governing by a concrete workability between initial vibration and repeated revibration.

This is a subject of the future study to investigate the propagation of the vibrating waves and their effect on the quality of the hardened concrete for Rollit Robot in comparision with other vibrator types. 


\section{REFERENCES}

1. W. A. K. Altowaiji et al: Bond of Reinforcement to Revibrated Concrete. ACI Journal. November-December 1986.

2. C. A. Vollic: Effects of Revibrating Concrete. ACI Journal. Proceedings. V. 54, No. 9. March. 1958, pp. 721-732.

3. W. J. Larnach: Changes in Bond Strength Caused by Revibration of Concrete and the Vibration of Reinforcement. Magazine of Concrete Research. London. V. 4, No. 10, July 1952, pp. 17-21.

4. R. E. Davis et al: Some Factors Influencing the Bond Between Concrete and Reinforcing Steel. Proceedings. ASTM, V. 38, Part 2, 1938, pp. 394-406.

5. R. C. Danahey et al: Effects of Construction Procedures on Bond in Bridge Decks. SM Report No. 7, University of Kansas Center for Research, Lawrence, January 1983.

6. S. Harsh et al: Traffic Induced Vibrations and Bridge Deck Repairs. Concrete International: Design \& Construction. V. 8, No. 5. May 1986, pp. 36-42.

7. W. Altowaiji et al: Preliminary Study of the Effect of Revibration on Concrete-Steel Bond Strength. SL Report No. 84-2. University of Kansas Center for Research, Lawrence, November 1984.

8. Nase-cho, Totsuka-ku, Yokohama. Taisei Technical Research Report No. 18, 0387-2254. March 1986.

9. D. Whiting. Air Contents and Air-Void Characteristics in Low-Slump Dense Concretes. Journal of the ACI. V. 82, No. 5, p.716-723. 1985.

\section{GLOSSARY}

Delayed vibration is a vibration at some period after the concrete had been placed.

Entrapped air forms the air voids with diameter larger than 0.9-1 mm.

Entrained air is formed when air-entraining admixture are added to the fresh concrete.

$H S$ is high slump, $L S$ is low slump

Repeated revibration is an external vibration made with a certain time lap bt the Rollit Robot. Resurfacing is when the damaged upper part of the concrete has to be removed and replaced by a new concrete layer. 


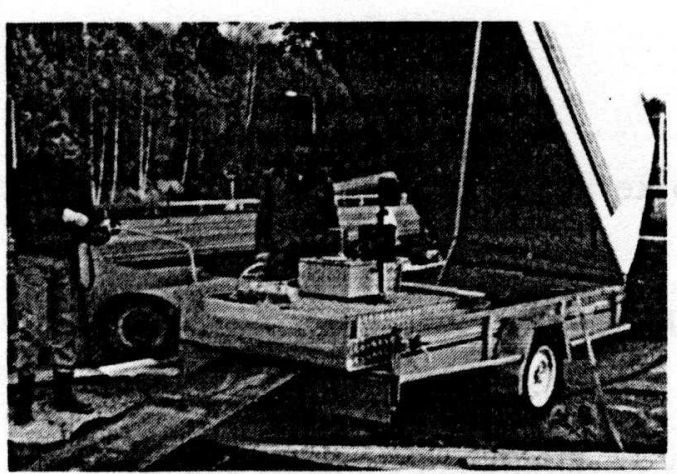

Fig.1 The Rollit Robot is transported to the site...

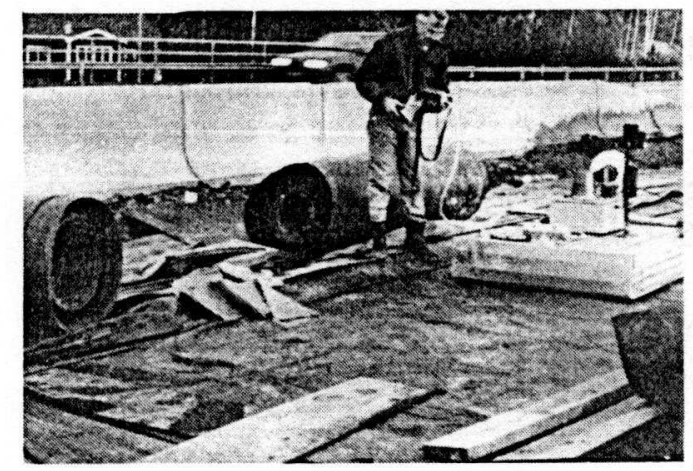

Fig.3..walking to the actual concrete placement area...

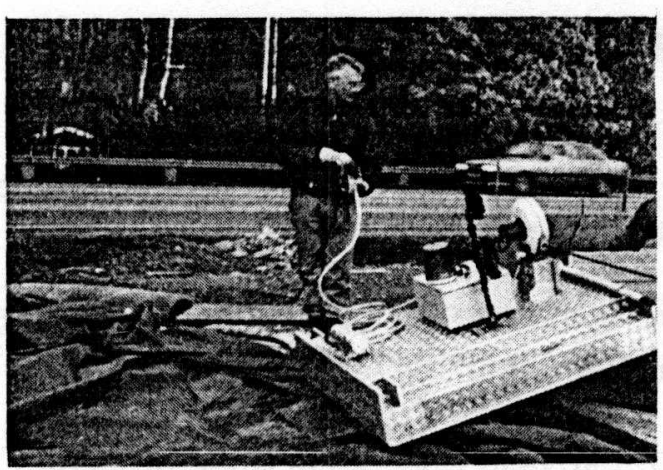

Fig.2..unloading itself...

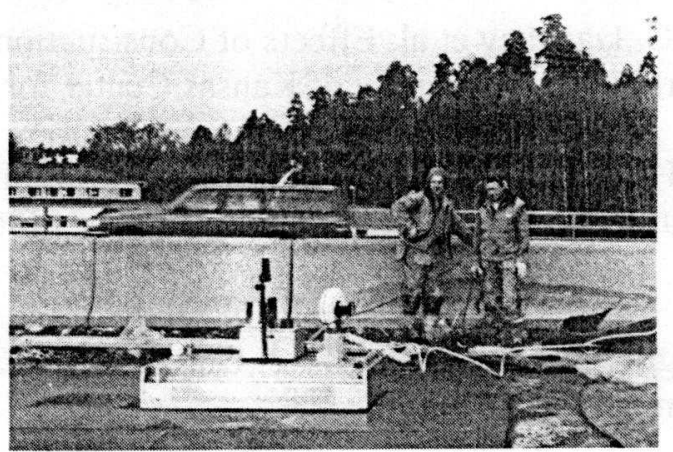

Fig.4.. and starting to work.

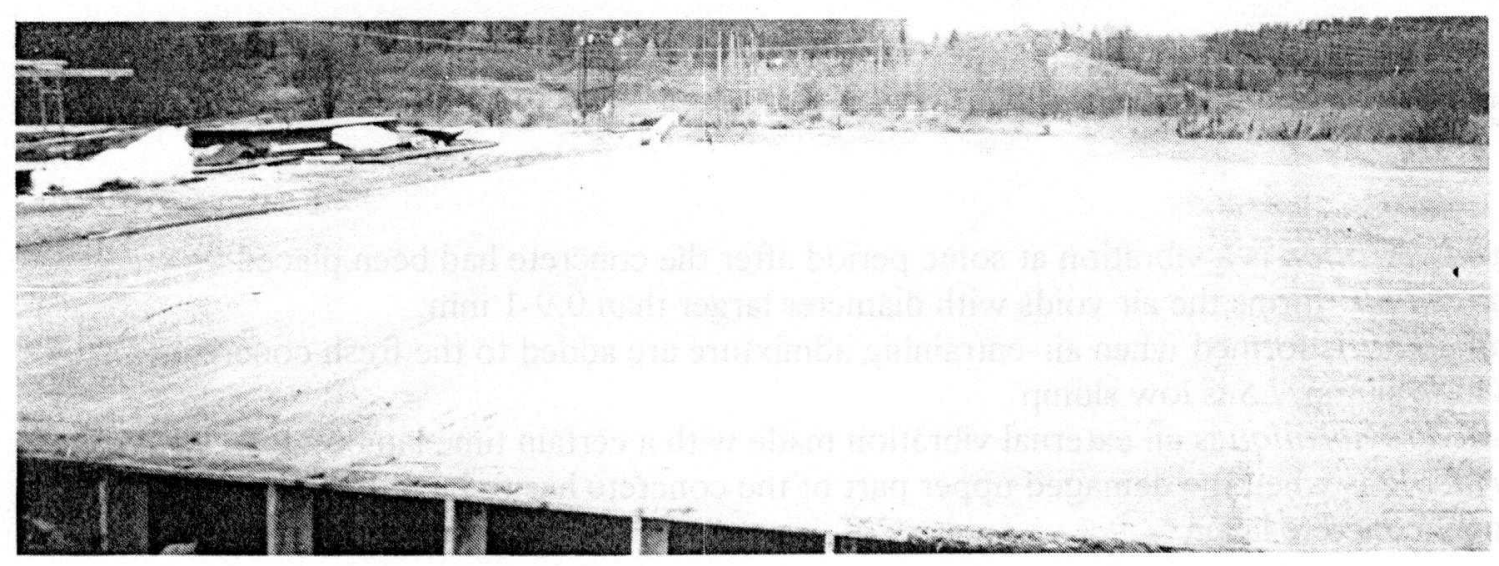

Fig.5 The left part of this area is revibrated and levelled with Rollit Robot-the last pass 3 hours after placement. 